\title{
Self-serving optimism in hedonic prediction: People believe in a bright future for themselves and their friends, but not for their enemies
}

\author{
Hallgeir Sjåstad ${ }^{1}$, Siv Skard ${ }^{1}$, Helge Thorbjørnsen ${ }^{1}$ and Elisabeth Norman ${ }^{2}$ \\ ${ }^{1}$ Department for Strategy and Management, $\mathrm{NHH}$ - Norwegian School of Economics \\ ${ }^{2}$ Faculty of Psychology, University of Bergen
}

\begin{abstract}
According to longitudinal research, psychological well-being is remarkably stable over time. However, people may still believe that the future will deviate from the past. Across three experiments in Norway and USA ( $N=1,130$; two pre-registered), participants were randomly assigned to report their well-being in the past or predict their future well-being. In line with a "bright-future hypothesis", people predicted higher levels of happiness and meaning in the future than their historical baseline from the past. We observed the same optimistic pattern for a 5-year horizon as a 1-year horizon, and participants who viewed themselves as pessimistic were no exception. Rather than being a cognitive illusion, the evidence favored a motivational explanation. Specifically, the effect was found both in separate judgment between-persons and joint evaluation within-persons, which means that participants did not "correct" their predictions even when the contrast with their own past became explicit (Study 2). This suggests that the participants believed that their future optimism was rational and accurate, although it deviates from their personal experience and is statistically unrealistic. Highlighting the social dimension of well-being predictions, our final experiment found that the expectation of future improvement generalized to judgments of a friend, but not to an enemy (Study 3). Seen as a whole, the results suggest that people predict a bright future when they want to see one.
\end{abstract}

Keywords: Optimism; prediction; future thinking; happiness; meaning

Manuscript length: 5,097 words

\section{Open Science:}

In two out of three experiments (studies 2 and 3), the hypotheses and statistical analyses were preregistered in advance of the data collection. In the event of publication, data and materials for all three experiments will be made openly available at the OSF platform.

\section{Author contact:}

Correspondence concerning this article should be addressed to Hallgeir Sjåstad, Department for Strategy and Management at NHH - Norwegian School of Economics.

E-mail: $\underline{\text { Hallgeir.Sjastad@nhh.no. }}$

\section{Funding:}

This work was partially supported by the Research Council of Norway through its Centres of Excellence Scheme, FAIR project No 262675. 


\section{Introduction}

Does tomorrow look a bit brighter than yesterday? To understand how people make decisions and navigate through their lives, it is crucial to understand how they think about the future (Suddendorf \& Corballis, 2007; Gilbert \& Wilson, 2007; Baumeister, Maranges, \& Sjåstad, 2018). The central question in the current investigation, is whether people expect their future well-being to systematically exceed their well-being in the past. We refer to this notion as the "bright-future hypothesis", and test two competing explanations for such an effect: cognitive illusions versus motivated beliefs. Unlike previous research, we will also examine the social dimension of well-being predictions.

\section{Broadening the scope of prediction research}

Since the seminal work on heuristic judgment of probability (Tversky \& Kahneman, 1973; Kahneman \& Tversky, 1979), psychological research on prediction has been rooted in two streams of literature. In the first, focusing on future life outcomes, studies on "unrealistic optimism" have found that people systematically overestimate the probability for positive events happening to them, and underestimate personal risk for negative events (Weinstein 1980; Shepperd et al, 2013). Related work has shown that people tend to see themselves as above average on a broad range of desirable traits (Alicke, 1985; Tappin \& McKay, 2017), and in many cases, subjective confidence in one's knowledge level (Kruger \& Dunning, 1999) and prediction accuracy (Tetlock, 2005) is only loosely connected to reality.

The second stream has focused on how people predict their emotional responses to specific events, often referred to as "affective forecasting" (Wilson \& Gilbert, 2005). In general, people tend to overestimate their future emotions and underestimate their capacity for hedonic adaptation (Frederick \& Loewenstein, 1999). Both cognitive (Schkade \& Kahneman, 1998; Wilson et al., 2000) and motivational mechanisms (Morewedge \& Buechel, 2013) have been identified for such effects. 
These two approaches were combined in a recent study addressing how the belief in "karma" can influence the prediction of both external events and specific emotions (Mata \& Simao, 2019).

However, when people think about the future, they may also consider additional factors than the mere probability of single events and how those events would make them feel. People also seem to care a great deal about their global well-being, including the search for meaning and long-term happiness (Frankl, 1946; Baumeister, Vohs, Aaker, \& Garbinsky, 2013; Dwyer, Dunn, \& Hershfield, 2017). For instance, clinical depression is widely known as a deeply aversive and uncomfortable condition, in part because the experience of emotional negativity and loss of hope is perceived as global and eternal, rather than local and short-lived (Beck, 1976; WHO, 2017). At the other end of the spectrum, people who are generally happy in life tend to have better social relationships (Diener \& Seligman, 2002) and they also tend to be more productive (Wright \& Staw, 1999; Oswald, Proto, \& Sgroi, 2015). Thus, global well-being is a central concern and a desirable ideal to many people (Diener \& Scollon, 2003), which makes it an interesting study target for the psychology of prediction.

\section{Time asymmetries in human judgment}

The current investigation is guided by the hypothesis that people expect their future well-being to systematically exceed their baseline from the past. In line with longitudinal research showing that actual life satisfaction tends to be highly stable over time (Eid \& Diener, 2004; Hudson et al., 2017), such as from one year to the next, we treat people's past well-being as the statistical standard for comparison. To be sure, there is cross-cultural evidence that people tend to experience certain longterm changes in their psychological well-being over the life-span, typically taking the form of a Ushaped trend with the lowest level of well-being occurring in middle age (Blanchflower \& Oswald, 2018). But on shorter time scales, such as from one year to the next, stability has been the dominant finding in the literature. We therefore make the assumption that if people are realistic about their near future, their global well-being predictions should not, on average, be systematically higher than their reports of the recent past. 
Time asymmetries between past and future have been documented in several domains of human judgment, finding a prospective increase in perceived control of external events (Rothbart \& Snyder, 1970), causal attribution to one's will (Helzer \& Gilovich, 2012), rational capacity (O'Brien, 2015), self-enhancing trait evaluations (Kanten \& Teigen, 2008), event valuation (Caruso, Gilbert, \& Wilson, 2008), moral judgment of self (Sjåstad \& Baumeister, 2019), moral judgment of others (Caruso, 2010), envious reactions to the success of others (Kristal, O'Brien, \& Caruso, 2019), and selfdeceptive happiness judgments (Robinson \& Ryff, 1999). Multiple explanations are possible for these findings, but a common theme seems to be that people perceive the future as more open and changeable than the past (Baumeister, Maranges, \& Sjåstad, 2018).

However, if the bright-future hypothesis is correct, it is still not clear what the specific mechanism of a such a time asymmetry would be. In the current investigation, we will test two competing explanations: cognitive illusions versus motivated beliefs.

\section{Cognitive illusions or motivated beliefs?}

If anticipated improvement in future well-being is mostly due to a cognitive illusion, it should be eliminated by changing the response format from separate judgment (between-persons) to joint evaluation (within-persons). The "illusion" here would be that the future might appear to be unrealistically positive until the past has been made salient as a comparison standard. For example, people's tendency to drastically underestimate the completion time for future tasks, known as the planning fallacy (Kahneman \& Tversky, 1979), can be mitigated by having them first report their actual completion time for similar tasks in the past (Buehler, Griffin, \& Ross, 2002). Moreover, the surprising tendency to place a higher value on the life of an endangered animal than a human worker in separate judgment is reversed when the same question is presented as joint evaluation (Kahneman \& Ritov, 1994). A dominant interpretation of such findings (Caruso, Gilbert, \& Wilson, 2008), is that people only believe that their inconsistencies are rational if they are still making the same judgment when both alternatives are visible and directly comparable (see also: Hsee, 
Loewenstein, Blount, \& Bazerman, 1999). Thus, if the expectation of a past-future asymmetry in wellbeing judgments is driven by a past-neglecting cognitive illusion, then such an effect should be eliminated when changing the response format from separate evaluation (responding to past or future questions) to joint evaluation (responding to past then future questions).

The alternative account, motivated beliefs, would explain the asymmetry as a consequence of people wanting the future to be better than the past. Anticipated improvement in global wellbeing should then remain even when changing the response format from separate judgment to joint evaluation. That is, if people are driven by self-enhancement motives (Sedikides \& Gregg, 2008; von Hippel \& Trivers, 2011), they should still predict a better future even when they just reported a lower baseline in their past. Indeed, related work suggests that it is fully possible that wanting becomes believing when people try to predict the future. Research on unrealistic optimism has documented that the estimated probability of a given event is positively correlated with the desirability of its outcome (Weinstein, 1980). The belief in a future that specifically favors the self has been found to be distinct from general optimism (Rogers, Moore, \& Norton, 2017). Moreover, a recent study found convincing evidence for "vicarious optimism", in which elevated concern for others led to underestimation of their future risk (Kappes, Faber, Kahane, Savulescu, \& Crockett, 2018).

\section{The social dimension of well-being predictions}

As a final test of the competing explanations of the bright-future effect, we also explored under what conditions the belief in future improvement would generalize to predictions on behalf of someone else. It is broadly documented that people have a need for belonging and social connection (Baumeister \& Leary, 1995; Cacioppo \& Patrick, 2008; Ryan \& Deci, 2000), and solve most challenges of survival and reproduction through cooperation and reciprocity (Baumeister, 2005; Nowak \& Highfield, 2011; Tomasello, 2016; von Hippel, 2018). If the expectation of a bright future is driven by a cognitive neglect of the past, whether we think the target person actually deserves to be happy shouldn't influence the overall judgment. From a motivated-belief perspective, however, what we 
want is highly relevant to what we believe, which suggests that optimistic prediction bias should be eliminated on the behalf of personal enemies but maintained for ourselves and our friends. If so, that would provide a novel contribution to the social psychology of well-being predictions, going beyond previous research that has focused exclusively on beliefs about the self (Robinson \& Ryff, 1999).

\section{Research overview}

In three experiments ( $N=1,030$; two pre-registered) across two different countries (Norway and USA), the present investigation explored the bright-future hypothesis: The time-inconsistent tendency to predict higher levels of well-being in the future than in the equidistant past.

Study 1 ( $N=194)$ compared future versus past happiness in separate ratings betweenpersons. The time scale was 5 years back versus 5 years ahead. In the remaining studies, participants reported their well-being either 1 year back or 1 year ahead. Study $2(N=300)$ combined measures of separate judgment between-persons and joint evaluation within-persons, and included measures of both happiness and meaning to get a broader assessment of global well-being. Study $3(N=565)$ relied exclusively on within-person ratings of past versus future well-being, in which the target was varied between-persons: Judgments of happiness and meaning were made either on behalf of themselves, a friend, or an enemy. The data collection for the three experiments were conducted in the months of March (Study 1), November (Study 2) and December (Study 3). All measures, manipulations, and exclusions are reported in each study. The sample size of each experiment was informed by a sensitivity power analysis, and determined prior to the data collection and statistical analysis.

Across studies, we found strong support for the bright-future hypothesis: The participants predicted higher levels of happiness and meaning in the future than they had experienced in the past. Contrary to our initial prediction, however, the results favored a motivated-belief explanation over the cognitive-illusion account. 


\section{Study 1}

Study 1 tested the bright-future hypothesis regarding general happiness in life. Specifically, we predicted that people would expect to feel happier in the future ( 5 years ahead) than they had felt in the past ( 5 years back). We used a between-persons design with two conditions, in which people reported either their past happiness or predicted their future happiness.

\section{Method}

Participants. Following two undergraduate lectures, we recruited 194 participants (142 female, age $M=22.3$ years) from a Norwegian student sample. All participants were compensated with a gift card at a local coffee shop worth $\$ 3$. A sensitivity analysis in the G*power software (Faul, Erdfelder, Lang, \& Buchner, 2007) found that this sample provided $80 \%$ power to detect an effect size of Cohen's $d=0.40$ or larger ( $p<.05$, two-tailed).

Materials and procedure. Participants filled out a short questionnaire about "personality and attitudes" in a paper-and-pencil format. They were randomly assigned to a past condition or a future condition, in a between-persons design.

The first part of the experimental manipulation was administered on the first page of the questionnaire. Participants were instructed to stop for a moment and think either about their future, five years ahead, or to think about their past, five years back. On the subsequent page, participants were asked to either report how happy they thought they would be in the future or how happy they had been in the past, using a similar rating scale from 0-10.

In the future condition, the headline stated: "In the future - in the next 5 years of your life:", in which participants responded to a single-item measure of predicted happiness on a 11-point rating scale: "In general, how happy do you think you will be?" ( $0=$ Not at all happy, $10=$ Very happy). In the past condition, the headline stated: "In the past - in the last 5 years of your life:", followed by a 
measure of remembered happiness: "In general, how happy have you been?" ( $0=$ Not at all happy, $10=$ Very happy)

\section{Results}

In line with the bright-future hypothesis, an independent $t$-test found that participants predicted to feel happier in the future than they had felt in the past $(M=7.72, S D=1.51 \mathrm{vs.} M=6.65$, $S D=1.85)$. This difference was statistically significant, and the effect size was above medium in strength, $t(192)=4.40, p<.001, d=0.63(95 \% \mathrm{Cl}=0.59,1.55)$. This means that the average expectation was that the future would systematically exceed the past in terms of psychological wellbeing.

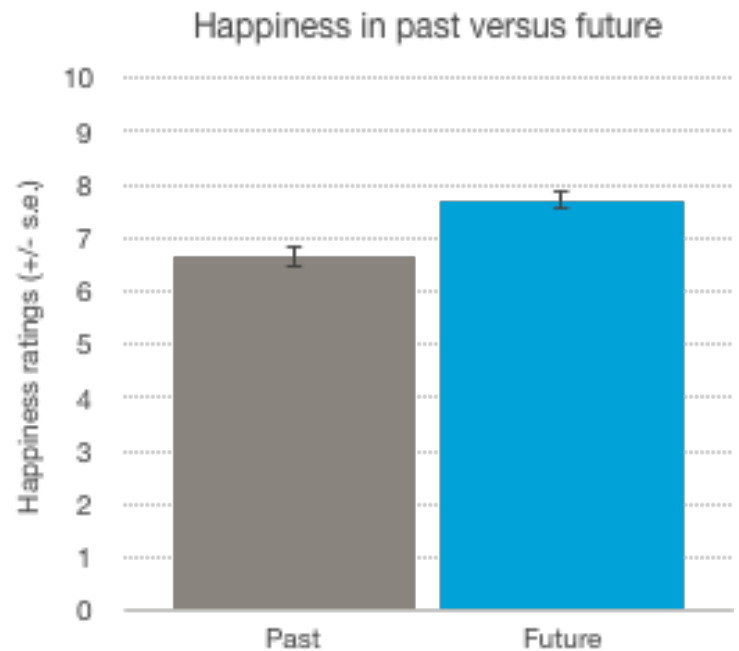

Figure 1: Study 1, Norway ( $\mathrm{N}=194)$. In line with the bright-future hypothesis, participants in the future condition predicted higher levels of happiness than the retrospective report in the past condition $(p<.001, d=0.63$ ). The happiness rating was made on an identical scale from 0 to 10. Error bars represents standard error.

\section{Study 2}

Study 2 tested an extended version of the bright-future hypothesis by including meaning in life as a second outcome measure. The central hypothesis was that people would predict to feel more happiness and meaning in the future than in the past. In addition, we wanted to explore whether such an effect would be counteracted by joint evaluation of past and future in a third condition (within-persons), which enabled a test of two competing explanations: cognitive illusions versus motivated beliefs. 


\section{Method}

Participants. We recruited 300 American participants (165 female, age $M=30$ years) from an online sample at Amazon Mechanical Turk ("Mturk"), for a brief research survey on attitudes and decisions. All participants were compensated with $\$ 0.50$. A sensitivity analysis in the $\mathrm{G}^{*}$ power software found that this sample provided $80 \%$ power to detect an effect size of Cohen's $d=0.40$ or larger $(p<.05$, two-tailed). The hypotheses, method and statistical analysis were pre-registered in advance of the data collection (PDF: https://osf.io/dnek8/?view only=4a29b4ea4bd14f26a31b1593956a1995).

Materials and procedure. Participants reported their age and gender, before they read the instructions for the main part of the survey. In the future condition, the instruction read as follows: "The questions coming next will be about your life in the future. Before you proceed, please stop for a moment and think one year ahead from today." In the past condition, a similar prompt instructed participants to think about the past: "The questions coming next will be about your life in the past. Before you proceed, please stop for a moment and think one year back from today." On the next screen, a manipulation check asked participants to indicate what year and month it would be one year from now (future condition) or one year ago (past condition).

Next came the two outcome measures, happiness and meaning in life, which were presented on separate screens in counterbalanced order. Future condition: "During the next year: How happy do you think you will be, on average?" ( $0=$ Not happy at all, $10=$ Very happy $)$, and "During the next year: How meaningful do you think your life will be like, on average?" $(0=$ Not meaningful at all, 10 = Very meaningful). Past condition: "During the past year: How happy have you been, on average?" ( $0=$ Not happy at all, $10=$ Very happy $)$, and "During the past year: How meaningful have your life been like, on average?" ( $0=$ Not meaningful at all, $10=$ Very meaningful). The third condition consisted of both the past and future items, in that respective order.

At the end of survey, all participants responded to a filler task (BMIS mood scale), before they responded to the 13-item scale of trait self-control (Tangney et al., 2004). Although trait self- 
control was positively correlated with both happiness and meaning when controlling for condition $(p<.01)$, it did not moderate the bright-future effect neither within or between persons.

\section{Results}

Bright-future hypothesis: Separate judgments (between-persons). Replicating the finding from Study 1, an independent $t$-test showed that participants asked about their future predicted higher levels of happiness than participants reporting their past happiness, between-persons $(M=$ $7.03, S D=2.23$ vs $M=5.67, S D=2.54)$. This difference was statistically significant, and the standardized effect size was of medium strength, $t(199)=4.02, p<.001, d=0.57(95 \% \mathrm{Cl}=0.69$, 2.02).

A similar test showed that participants also predicted more meaning in life in the future than the past reports, between-persons $(M=7.00, S D=2.36$ vs $M=5.85, S D=2.69)$. This difference was again statistically significant, and the standardized effect size was of medium strength, $t(199)=3.22$, $p=.001, d=0.45(95 \% \mathrm{Cl}=0.45,1.85)$. Thus, in line with the bright-future hypothesis, people expected more happiness and meaning in the future than they had experienced in the past.

Bright-future hypothesis: Joint evaluation (within-persons). More surprisingly, paired sample $t$-tests on joint evaluation in the within-persons condition also found that participants predicted a higher level of well-being in the future than they had just reported in the past. Specifically, participants predicted significantly more happiness in the future than the past $(M=7.31$, $S D=2.53$ vs $M=6.44, S D=2.83, p<.001, d=0.52,95 \% \mathrm{Cl}=0.52,1.21)$, and significantly more meaning in the future than the past $(M=7.10, S D=2.40$ vs $M=6.01, S D=2.85, p<.001, d=0.59$, $95 \% \mathrm{Cl}=0.72,1.46)$.

We note that this particular finding runs contrary to our initial prediction, which was that the bright-future effect should be eliminated in the joint evaluation format. It also differs from previous research on the planning fallacy (Kahneman \& Tversky, 1979), in which overly optimistic predictions 
is mitigated by considering one's past performance before making the prediction (Buehler, Griffin, \& Ross, 2002). After seeing this result, we revised our prior from a cognitive to a motivational explanation. Study 3 was therefore designed to replicate this effect, and test our updated hypothesis with greater precision.
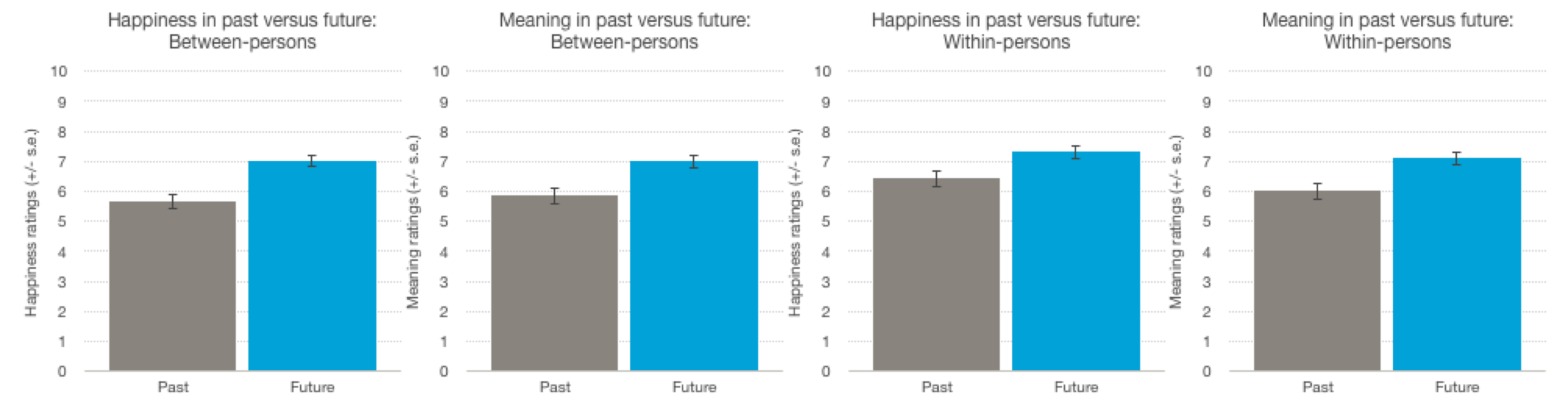

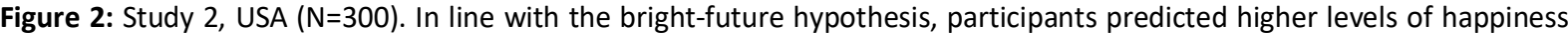
and meaning in the future than they reported in the past. From the left panel towards the right, this effect was found both in separate judgment between-persons (happiness: $p<.001, d=.57$; meaning: $p=.001, d=.45$ ) and in joint evaluation withinpersons (happiness: $\mathrm{p}<.001, \mathrm{~d}=.52$, meaning: $\mathrm{p}<.001, \mathrm{~d}=.59$ ). All ratings were made on a scale from 0 to 10 . Error bars represents standard error.

\section{Study 3}

In Study 3, we tested the bright-future hypothesis when participants made well-being predictions on the behalf of themselves, a good friend, or a personal enemy. This design enabled an extended test of competing explanations. The central hypothesis was that people would predict a happier and more meaningful future for themselves, as compared to their own reports of their recent past. In line with a motivated-belief explanation, the novel prediction was that the bright-future effect would also generalize to the judgment of a friend, but not to an enemy.

\section{Method}

Participants. We recruited 636 American participants from an online sample at Amazon's Mechanical Turk. After removing participants who failed the manipulation checks $(N=41)$ and those who did not complete the survey $(N=30)$, we were left with a final sample of 565 participants (321 female, age $M=39$ years). A sensitivity analysis in the $\mathrm{G}^{*}$ power software found that this sample provided $80 \%$ power to detect an effect size of Cohen's $d=0.29$ or larger $(p<.05$, two-tailed). The 
hypotheses, method and statistical analysis were pre-registered in advance of the data collection (PDF: https://osf.io/dnek8/?view only=4a29b4ea4bd14f26a31b1593956a1995).

Materials and procedure. Participants reported their age and gender, before they read the survey instructions. As all participants reported their past and future well-being using identical rating scales as in Study 2, the experimental manipulation was whether they responded to these questions on behalf of themselves, a good friend, or a personal enemy. Participants were randomly assigned to one of the three target person conditions in a between-persons design (self vs friend vs enemy), and typed in the initials of their target person before reporting their judgments of past and future wellbeing. To make sure that participants followed the instruction, they were asked to type in the initials of the target person (self, friend or enemy) before proceeding to well-being judgments.

For exploratory purposes, we also asked participants to rate to what extent they viewed the target person as someone who deserved well-being, was capable of making the right decisions to create well-being, and was a lucky person. All measures were completed on a scale from 0 to 10 , anchored at 'Not at all' (0) and 'Very much so' (10). At the end of the study, we asked participants to rate the extent to which they viewed themselves as an optimistic person $(0=$ Not at all, $10=$ Very much so).

\section{Results}

Bright-future hypothesis: Self, friend, enemy. As described in the pre-registered analysis plan, the predicted improvement in general well-being was computed as a difference score between future and past well-being: (Future happiness + future meaning/2) - (Past happiness + past meaning/2). A higher difference score indicates greater predicted improvement, and the value zero would indicate no predicted change from past to future.

In line with the bright-future hypothesis, a one-way between-groups ANOVA showed a significant difference between the three groups on predicted improvement in global well-being from past to future $\left(F(2,562)=17.87, p<.001\right.$, partial $\left.\eta^{2}=.06\right)$. In line with the motivated-belief 
explanation, Tukey post-hoc analyses showed that compared to the prediction on the behalf of their enemies $(M=-.02, S D=1.36)$, participants predicted greater future improvement in well-being for their friends $(M=+.56, S D=1.10, p<.001)$ and themselves $(M=+.69, S D=1.17, p<.001)$.

Paired samples $t$-tests for each of the three conditions provided additional support to the motivational account of the bright-future hypothesis. Comparisons between past and future ratings in each condition showed that participants predicted significantly greater well-being for themselves in the future $(M=7.00, S D=2.28)$ than the past $(M=6.31, S D=2.34, t(197)=8.29 p<.001, d=0.59$, $95 \% \mathrm{Cl}=0.53,0.86)$, and they also predicted significantly greater well-being for their friends in the future $(M=7.71, S D=1.61)$ than in their past $(M=7.16, S D=1.85, t(184)=6.88, p<.001, d=0.50$, $95 \% \mathrm{Cl}=0.40,0.72)$. However, when making the same prediction on the behalf of their enemies, there was no positive difference between predicted well-being in the future $(M=4.72, S D=2.45)$ and the enemy's well-being in the past $(M=4.73, S D=2.20, \mathrm{t}(181)=.16, p=.87, d=-0.01,95 \% \mathrm{Cl}=-$ $0.22,0.18)$. That is, participants predicted higher levels of happiness and meaning in the future than the past only when the judgment was made on behalf of themselves or a good friend, whereas no such effect was found when the same judgment was made for a personal enemy.

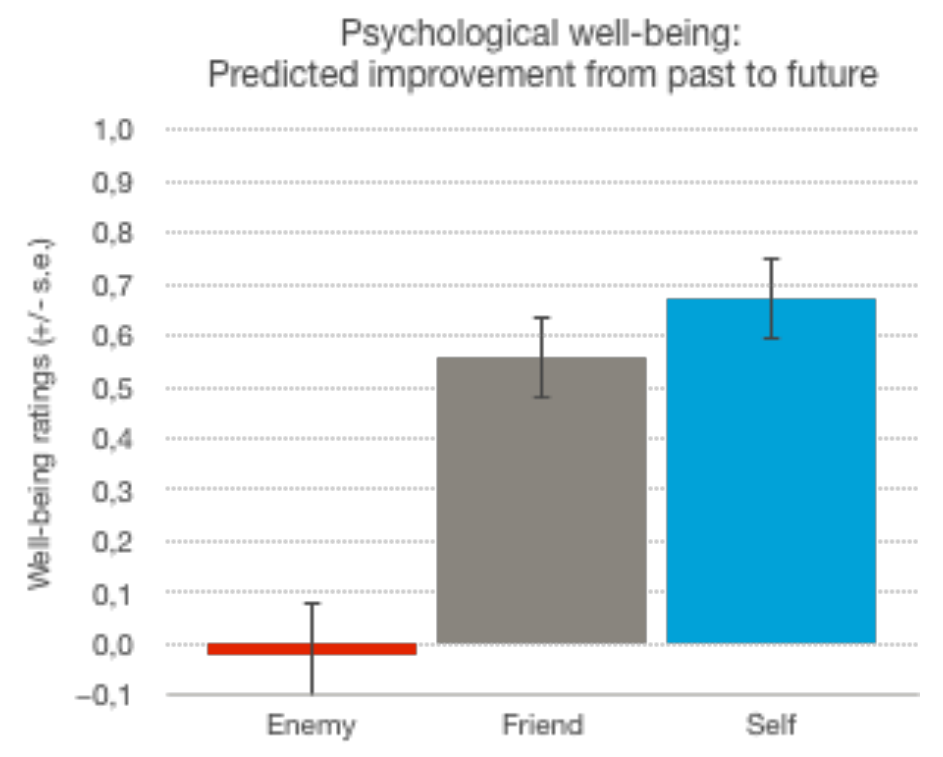

Figure 3: Study 3, USA ( $N=565$ ). In line with the bright-future hypothesis, participants predicted higher levels of psychological well-being in the future than the past. In line with a motivational explanation, this effect was found when participants made the judgment for themselves $(p<.001, d=.59)$ and a friend $(p<.001, d=.50)$, but not for a personal enemy $(p=.87, d=-.01)$. Predicted improvement was computed by subtracting ratings of past well-being (happiness+meaning/2) from predicted wellbeing in the future (happiness+meaning/2), in which the value zero (0) would mean no predicted change. All ratings were made on a scale from 0 to 10 . Error bars represents standard error. 
Attribution measures: Self, friend, enemy. Turning to the exploratory attribution measures, we conducted a series of ANOVAs with condition as the independent variable and the three forms of attributions as dependent variables. This analysis found a significant effect of condition on whether the participants believed that the target person deserved well-being $(F(2,562)=111.05, p<.001$, partial $\left.\eta^{2}=.28\right)$, was likely to make the right decisions to create well-being $(F(2,562)=138.85, p<$ .001 , partial $\left.\eta^{2}=.33\right)$, and tended to have luck on their side $\left(F(2,562)=18.98, p<.001\right.$, partial $\eta^{2}=$ $.06)$.

A non-registered analysis using Tukey post hoc comparisons showed that the participants believed that their enemies deserved well-being to a lesser extent $(M=3.39, S D=1.86)$ than a friend $(M=5.58, S D=.78, p<.001)$ and themselves $(M=4.78, S D=1.44, p<.001)$, and also thought that their enemies were less likely to make the right decisions to produce well-being $(M=2.45, S D=1.72)$ as compared to their friends $(M=4.80, S D=1.37, p<.001)$ and themselves $(M=4.56, S D=1.36, p<$ .001). In our view, these findings validate the motivational assumption: A high rating of deservingness and decision ability suggests that the participants also wanted to see higher levels of well-being in the future of themselves and their friends.

Finally, participants did not think that their enemies tended to have more luck and coincidences on their side $(M=3.10, S D=1.64)$ than themselves $(M=3.25, S D=1.82, p=.675)$, although they did expect that their friends would have significantly more luck $(M=4.08, S D=1.45)$ than both themselves $(p<.001)$ and their enemies $(p<.001)$.

Self-assessed optimism. Moderation analyses using PROCESS (Hayes, 2013) found that selfassessed optimism did not moderate the effect of target person on predicted improvement in wellbeing. Further, moderation analyses using MEMORE (Montoya \& Hayes, 2017) found no moderation of self-assessed optimism on the difference between future and past well-being for each target person. When including self-assessed optimism as a control variable, the bright-future effect on predicted improvement remained highly significant both for self $(p=.001)$ and friend ratings $(p=$ 
.003). Seen as a whole, this suggests that the tendency to believe in a better future for oneself and one's friends was found even among individuals who viewed themselves as rather pessimistic by disposition.

\section{General Discussion}

Three experiments $(N=1,030)$ from two different countries provided strong support for the "brightfuture hypothesis". Although longitudinal research has demonstrated that psychological well-being is remarkably stable over time (Eid \& Diener, 2004; Hudson et al., 2017), our participants showed a time-inconsistent pattern by predicting more happiness and meaning in the future than they had experienced in the past. The same effect emerged for a 5-year horizon as a 1-year time horizon, for "general" and average estimates, and for Norwegian and American participants.

\section{Motivated prediction}

As our most important contribution, we tested two competing explanations for the bright-future effect: cognitive illusions versus motivated beliefs. Contrary to our initial prediction, the results supported the motivated-belief explanation.

Specifically, the same optimistic time-asymmetry was found both in separate judgment between-persons and joint evaluation within-persons, which means that the optimistic pattern cannot be attributed to a simple neglect of the past. Even when the participants reported their past well-being on identical scales just seconds before, they still predicted higher levels of happiness and meaning in the future (within-persons). At least to some extent, this suggests that people believe that their own optimism is rational and accurate, and not in need for cognitive "correction" (Caruso, Gilbert, \& Wilson, 2008; Hsee, Loewenstein, Blount, \& Bazerman, 1999). Providing further evidence for a motivational explanation, people generalized the optimistic prediction to their friends but not to their enemies. This suggests that people predict future improvement when they want to see one, and it also underscores the social dimension of motivated well-being predictions. Finally, the 
tendency to expect more well-being in the future than the past was found even among individuals who viewed themselves as rather pessimistic, suggesting that the effect is not dependent on optimistic personality traits.

These findings extend a previous study by Robinson and Ryff (1999), who showed that American participants predicted to be happier 5 years from now than they were 5 years ago. They also found that the prediction of future happiness was positively correlated with self-deceptive ratings, and counteracted when future uncertainty was reduced. In our view, this fits well to the motivational account and the present results. In the current experiments, we sought to replicate and extend this work to judgments of both happiness and meaning, both for the self and others, which in turn provided a broader test of the psychological mechanism: Motivated beliefs.

\section{Implications and future directions}

From the perspective of behavioral economics, the current findings might be a manifestation of socalled belief-based utility (Loewenstein \& Molnar, 2018), in which certain attitudes and convictions are held because they provide intrinsic value -- such as hedonic pleasure or meaning in life. That is, people can derive utility from anticipation, not only current experiences, so expecting future improvement can in itself lead to greater well-being. According to evolutionary accounts of selfdeception (Trivers, 1976), optimism and other forms of overconfidence might also have a social function in persuading others more effectively (von Hippel \& Trivers, 2011; Smith, Trivers, \& von Hippel, 2017; Schwardmann \& van der Weele, 2019).

Future research in psychology and social science may therefore examine whether the current pattern of "tribal optimism" provides a combination of hedonic and interpersonal benefits to the person: A tendency to expect future improvement for oneself and one's friends, but not for one's enemies. It could be the case that expressing such expectations is taken as a signal for trustworthiness and loyalty, and perhaps a broader willingness to cooperate with the ingroup and compete with the outgroup. In social life, people might appreciate and reinforce a certain level of 
future optimism in their peers, even when their plans and predictions are statistically unrealistic. A second possibility in future research, could be to include a present-oriented control condition to examine whether people expect future improvement also is comparison to their current well-being. In our investigation, we focused on past versus future to keep the time scale constant and directly comparable (i.e., thinking one year back vs one year ahead), which also makes it easier to assess the realism of the prediction. That said, it would be interesting to know whether people believe in consistent improvement over multiple time points, including both past, present and future.

For now, we conclude that a series of three experiments provided robust evidence for selfserving optimism in hedonic prediction, termed the bright-future effect, and that motivated beliefs appears to be the most likely explanation. 


\section{References}

Alicke, M. D. (1985). Global self-evaluation as determined by the desirability and controllability of trait adjectives. Journal of Personality and Social Psychology, 49(6), 1621.

Baumeister, R. F. (2005). The cultural animal: Human nature, meaning, and social life. Oxford University Press.

Baumeister, R. F., Maranges, H. M., \& Sjåstad, H. (2018). Consciousness of the future as a matrix of maybe: Pragmatic prospection and the simulation of alternative possibilities. Psychology of Consciousness: Theory, Research, and Practice, 5(3), 223.

Baumeister, R. F., Vohs, K. D., Aaker, J. L., \& Garbinsky, E. N. (2013). Some key differences between a happy life and a meaningful life. The Journal of Positive Psychology, 8(6), 505-516.

Beck, A.T. (1976). Cognitive therapy and the emotional disorders. New York: International Universities Press.

Blanchflower, D. G., \& Oswald, A. J. (2008). Is well-being U-shaped over the life cycle? Social Science \& Medicine, 66(8), 1733-1749.

Buehler, R., Griffin, D., \& Ross, M. (2002). Inside the planning fallacy: The causes and consequences of optimistic time predictions. In T. Gilovich, D. Griffin, \& D. Kahneman (Eds.), Heuristics and biases: The psychology of intuitive judgment (pp. 250-270). New York, NY, US: Cambridge University Press.

Caruso, E. M. (2010). When the future feels worse than the past: A temporal inconsistency in moral judgment. Journal of Experimental Psychology: General, 139(4), 610.

Caruso, E. M., Gilbert, D. T., \& Wilson, T. D. (2008). A wrinkle in time: Asymmetric valuation of past and future events. Psychological Science, 19(8), 796-801.

Cacioppo, J. T., \& Patrick, W. (2008). Loneliness: Human nature and the need for social connection. WW Norton \& Company.

Diener, E., \& Scollon, C. (2003). Subjective well-being is desirable, but not the summum bonum. In University of Minnesota Interdisciplinary Workshop on Well-Being (pp. 23-25).

Diener, E., \& Seligman, M. E. (2002). Very happy people. Psychological Science, 13(1), 81-84.

Dwyer, R. J., Dunn, E. W., \& Hershfield, H. E. (2017). Cousins or conjoined twins: how different are meaning and happiness in everyday life? Comprehensive Results in Social Psychology, 2(2-3), 199-215.

Eid, M., \& Diener, E. (2004). Global judgments of subjective well-being: Situational variability and long-term stability. Social indicators research, 65(3), 245-277.

Faul, F., Erdfelder, E., Lang, A. G., \& Buchner, A. (2007). G* Power 3: A flexible statistical power analysis program for the social, behavioral, and biomedical sciences. Behavior Research Methods, 39(2), 175-191.

Frankl, V. E. (1946/2004). Man's search for meaning. Rider.

Frederick, S., \& Loewenstein, G. (1999). 16 Hedonic Adaptation. Well-being: The foundations of hedonic psychology, 302329.

Gilbert, D. T., \& Wilson, T. D. (2007). Prospection: Experiencing the future. Science, 317(5843), 1351-1354.

Helzer, E. G., \& Gilovich, T. (2012). Whatever is willed will be: A temporal asymmetry in attributions to will. Personality and Social Psychology Bulletin, 38(10), 1235-1246.

Hudson, N. W., Lucas, R. E., \& Donnellan, M. B. (2017). Day-to-day affect is surprisingly stable: a 2-year longitudinal study of well-being. Social psychological and personality science, 8(1), 45-54.

Hsee, C. K., Loewenstein, G. F., Blount, S., \& Bazerman, M. H. (1999). Preference reversals between joint and separate evaluations of options: a review and theoretical analysis. Psychological Bulletin, 125(5), 576.

Kahneman, D., \& Ritov, I. (1994). Determinants of stated willingness to pay for public goods: A study in the headline method. Journal of Risk and Uncertainty, 9(1), 5-37. 
Kahneman, D., \& Tversky, A. (1979). Intuitive prediction: Biases and corrective procedures. Management Science, 12, 313327.

Kanten, A. B., \& Teigen, K. H. (2008). Better than average and better with time: Relative evaluations of self and others in the past, present, and future. European Journal of Social Psychology, 38(2), 343-353.

Kappes, A., Faber, N. S., Kahane, G., Savulescu, J., \& Crockett, M. J. (2018). Concern for others leads to vicarious optimism. Psychological Science, 29(3), 379-389.

Kristal, A. C., O'Brien, E., \& Caruso, E. M. (2019). Yesterday's news: A temporal discontinuity in the sting of inferiority. Psychological Science, 30(5), 643-656.

Kruger, J., \& Dunning, D. (1999). Unskilled and unaware of it: how difficulties in recognizing one's own incompetence lead to inflated self-assessments. Journal of Personality and Social Psychology, 77(6), 1121.

Loewenstein, G., \& Molnar, A. (2018). The renaissance of belief-based utility in economics. Nature Human Behaviour, 2(3), 166.

Morewedge, C. K., \& Buechel, E. C. (2013). Motivated underpinnings of the impact bias in affective forecasts. Emotion, 13(6), 1023.

Nowak, M., \& Highfield, R. (2011). Supercooperators: Altruism, evolution, and why we need each other to succeed. Simon and Schuster.

O'Brien, E. (2015). Mapping out past and future minds: The perceived trajectory of rationality versus emotionality over time. Journal of Experimental Psychology: General, 144(3), 624.

Oswald, A. J., Proto, E., \& Sgroi, D. (2015). Happiness and productivity. Journal of Labor Economics, 33(4), 789-822.

Robinson, M. D., \& Ryff, C. D. (1999). The role of self-deception in perceptions of past, present, and future happiness. Personality and Social Psychology Bulletin, 25(5), 596-608.

Rogers, T., Moore, D. A., \& Norton, M. I. (2017). The belief in a favorable future. Psychological Science, 28(9), 1290-1301.

Ryan, R. M., \& Deci, E. L. (2000). Self-determination theory and the facilitation of intrinsic motivation, social development, and well-being. American psychologist, 55(1), 68.

Schkade, D. A., \& Kahneman, D. (1998). Does living in California make people happy? A focusing illusion in judgments of life satisfaction. Psychological Science, 9(5), 340-346.

Schwardmann, P., \& Van der Weele, J. (2019). Deception and self-deception. Nature Human Behaviour, 1-7.

Sedikides, C., \& Gregg, A. P. (2008). Self-enhancement: Food for thought. Perspectives on Psychological Science, 3(2), 102116.

Shepperd, J. A., Klein, W. M., Waters, E. A., \& Weinstein, N. D. (2013). Taking stock of unrealistic optimism. Perspectives on Psychological Science, 8(4), 395-411.

Sjåstad, H., \& Baumeister, R. F. (2019). Moral self-judgment is stronger for future than past actions. Motivation and Emotion, 1-19.

Smith, M. K., Trivers, R., \& von Hippel, W. (2017). Self-deception facilitates interpersonal persuasion. Journal of Economic Psychology, 63, 93-101.

Suddendorf, T., \& Corballis, M. C. (2007). The evolution of foresight: What is mental time travel, and is it unique to humans? Behavioral and Brain Sciences, 30(3), 299-313.

Tappin, B. M., \& McKay, R. T. (2017). The illusion of moral superiority. Social Psychological and Personality Science, 8(6), 623-631.

Tetlock, P. E. (2005). Expert Political judgment: How good is it? How can we know? Princeton University Press.

Tomasello, M. (2016). A natural history of human morality. Harvard University Press. 
Trivers, R. L. (1976). Foreword to the selfish gene (by R. Dawkins). Oxford: Oxford University Press.

Tversky, A., \& Kahneman, D. (1973). Availability: A heuristic for judging frequency and probability. Cognitive Psychology, 5(2), 207-232.

Von Hippel, W. (2018). The social leap: The new evolutionary science of who we are, where we come from, and what makes us happy. Harper Collins.

Von Hippel, W., \& Trivers, R. (2011). The evolution and psychology of self-deception. Behavioral and Brain Sciences, 34(1), $1-16$.

Weinstein, N. D. (1980). Unrealistic optimism about future life events. Journal of Personality and Social Psychology, 39(5), 806.

Wilson, T. D., \& Gilbert, D. T. (2005). Affective forecasting: Knowing what to want. Current Directions in Psychological Science, 14(3), 131-134.

Wilson, T. D., Wheatley, T., Meyers, J. M., Gilbert, D. T., \& Axsom, D. (2000). Focalism: a source of durability bias in affective forecasting. Journal of Personality and Social Psychology, 78(5), 821.

World Health Organization. (2017). Depression and other common mental disorders: Global health estimates (No. WHO/MSD/MER/2017.2). Retrieved at:

https://apps.who.int/iris/bitstream/handle/10665/254610/WHO-MSD-MER-2017.2-eng.pdf

Wright, T. A., \& Staw, B. M. (1999). Affect and favorable work outcomes: two longitudinal tests of the happy-productive worker thesis. Journal of Organizational Behavior: The International Journal of Industrial, Occupational and Organizational Psychology and Behavior, 20(1), 1-23. 